\title{
Hydroinformatic system (implementation in Thailand) ${ }^{\#}$
}

\author{
H Vathananukij* and S Malaikrisanachalee \\ Faculty of Engineering, Kasetsart University, 50 Paholyothin Rd., Bangkok10900, Thailand
}

\begin{abstract}
The first hydroinformatic system in Thailand originated from the National Water Resource Strategy of 2007. In order to manage different hydrological data format in text file, html file, access file and spreadsheet file from different institutes, an interactive data assimilation system was introduced. Acquisitive data from 1150 major hydrological stations were inspected, verified, reformatted and statistically analysed. This research performs processes of two successful versions of the Thailand Hydroinformatic System. Virtual mechanism can, however, increase public participation to attain and utilise both information and metadata under open source licence. At the time of publication, the effective utilisation of the international standard format (ISO19115) is implemented through the public domain system. This hydroinformatic system enlarges potentiality of national communities to truly realise the potential of their natural water resources and tangibly understand their water environment. This system is regarded as a nationally sustainable prototype system to improve water resource management capability.
\end{abstract}

Keywords: hydroinformatic system, public domain model, virtual system

\section{Introduction}

The Kingdom of Thailand is situated in the heart of the Southeast Asian mainland, occupying $513115 \mathrm{~km}^{2}$. The geographic form is composed of four natural features, namely mountain; plateau; central plain; and coastline and island. Thailand is a warm and humid tropical country which is influenced by monsoons in both wet and dry seasons. The country has faced serious disasters in terms of both flood and drought at times. Over the past 10 years, expansive droughts have occurred in the mountainous area (northern region) and the plateau area (northeastern region) during the dry season. During the rainy season flash floods and landslides in the upper basins accumulated in and overwhelmingly inundated the central plain during the same drought year. Faced with serious disasters in terms of drought and flood especially during 2002 and 2006, the Thai government was extremely concerned and fully realised the national urgency in addressing these important problems.

In the past, research on vertical resolution and the effect of map scale digital elevation models on parameters has been focused on hydrology and hydrological processes (Gyasi et al., 1995). Furthermore, the geographical information system (GIS) becomes an important tool of water resource management (Tsihrinzis et al., 1996) and the system of geographical information can be based on hydrological and hydraulic engineering applications (Olivera et al., 1999). Merging the geoinformatic system into the Thai database systems needs national standard format in each map scale and layer (Vathananukij, 2003) and network flow analysis is also very important in engineering management (Malaikisanachalee et al., 2005). Therefore, in 2007, the Thai-

Revised version. Originally presented at the International Conference on Integrated Water Resource Management (IWRM) entitled: Lessons from Implementation in Developing Countries which took place from 10 to 12 March 2008 in Cape Town, South Africa, at the Cape Town International Convention Centre.

* To whom all correspondence should be addressed.

+662 9428555 ext 1912; fax: +662 9428555 ext 1912;

e-mail: hansa.v@ku.ac.th land National Strategy stressed the need for hydroinformatic systems to support the national decision in an effort to address flood and drought problems. Complexity among numerous data, several formats, lack of available models and strategies could not effectively deal with the catastrophe. Fundamental difficulties lay mostly in the fact that initial inputs were both in hard copy format and analog systems. Hence, the Thailand Hydroinformatic System Prototype Project was initialised with precipitation data acquired by more than 1000 observation stations between 1994 and 2005.

\section{Research processes}

The processes were accomplished through:

- Standard database assimilation

- Interactive systems for community engagement strategy.

Standard database assimilation: The Thailand Hydroinformatic System maintains hydro-meteorological data from 1994 to 2005. Data retrieved from 1150 stations were inspected, verified, reformatted and statistically analysed. The historical precipitation and discharge data are from two departments, namely the Thai Meteorological Department (TMD) and the Royal Irrigation Department (RID). The TMD provides not only daily data but also geographical locations as well as descriptive information of data-gauging stations. The data from RID, however, are more difficult to process because they are encoded in a number of separate text files that complicate content structure. Although both departments maintain more than 1000 hydrometeorological gauging stations all over Thailand, many of them are not consistently functioning. Hence, initial inspection (quality processing) is required for discriminating stations with questionable reliability. The research objective is to study and develop all data into standard format as ISO19115 which could inspect and access data in terms of an interactive geoinformatic system on public domain system (International Standard 19115 Geographic Information-Metadata, 2003; Vathananukij, 2005; Malaikisanachalee et al., 2007). In order to reduce data-processing time as well as minimise human errors during data processing, a custom-made Java Script program is introduced to develop the semi-automatic 


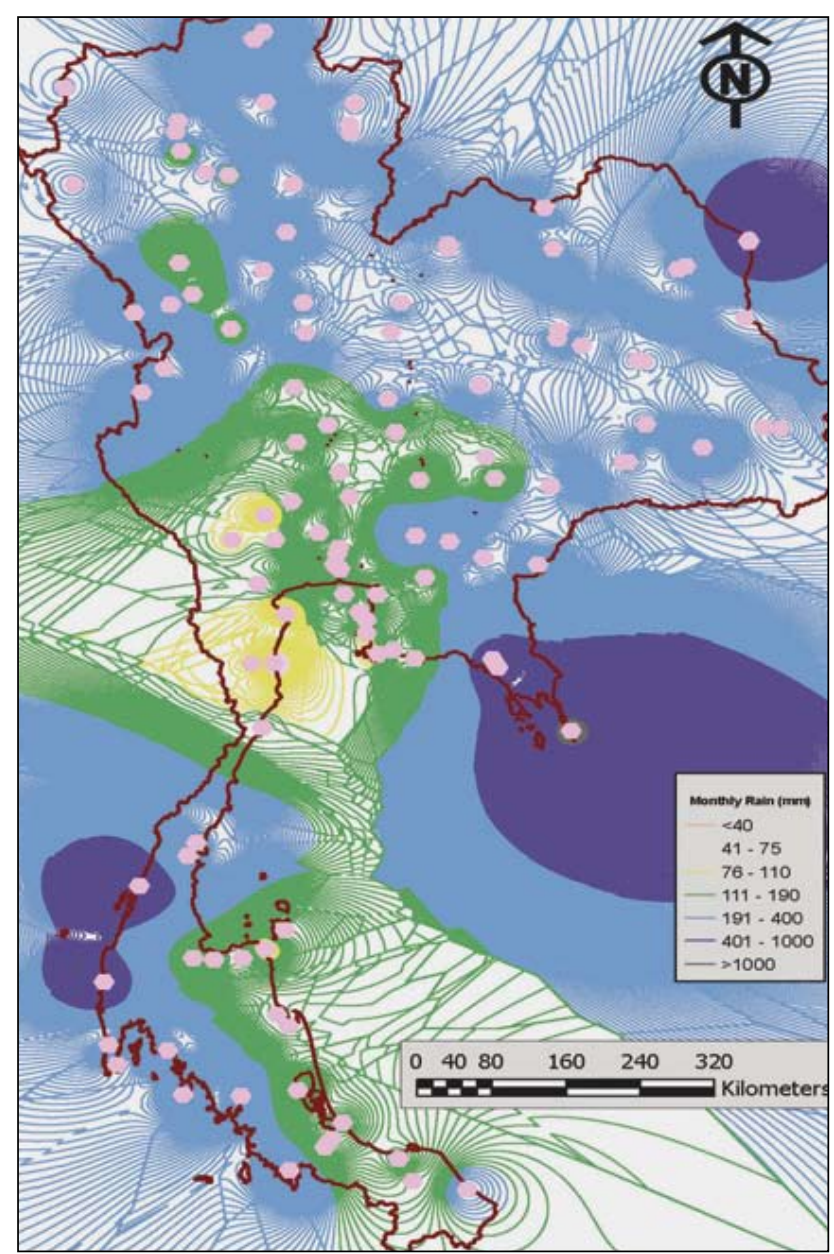

Figure 1

Mean monthly precipitation data

process for managing data from the complex text files. However, data integration and analysis for OS/OW permitting could facilitate and promote the data-sharing process (Adams et al., 2002). The implementation of metadata schema requires spatial data description (Malaikisanachalee et al., 2007) and interpolation techniques (Vathananukij, 1998). Mathematical techniques do take into consideration where all mass digital metadata is determined on spatial distribution. By being visible, providing the inverse-distance weighted approach or the Thiessen polygon approach to assist in benchmarking the mathematical interpolation, the process was able to establish a trusted presence into the database assimilation. Given in Eq. (1) are the mathematical formulation, variables and parameters used in the inverse distance weighted approach:

$$
\begin{array}{cl}
\hat{z}\left(x_{0}\right) & =\frac{\sum_{i=1}^{n} z\left(x_{i}\right) \cdot d_{i j}^{-p}}{\sum_{i=1}^{n} d_{i j}^{-p}} \\
\text { where: } & =\text { estimated pixel data } \\
z\left(x_{0}\right) & =\text { observed station i data } \\
z\left(x_{i}\right) & =\text { station distance } \\
d_{i j} & =\text { distance coefficient } \\
p & =\text { number of stations } \\
n &
\end{array}
$$

As can be seen from Fig. 1, the production of a case study on mean monthly

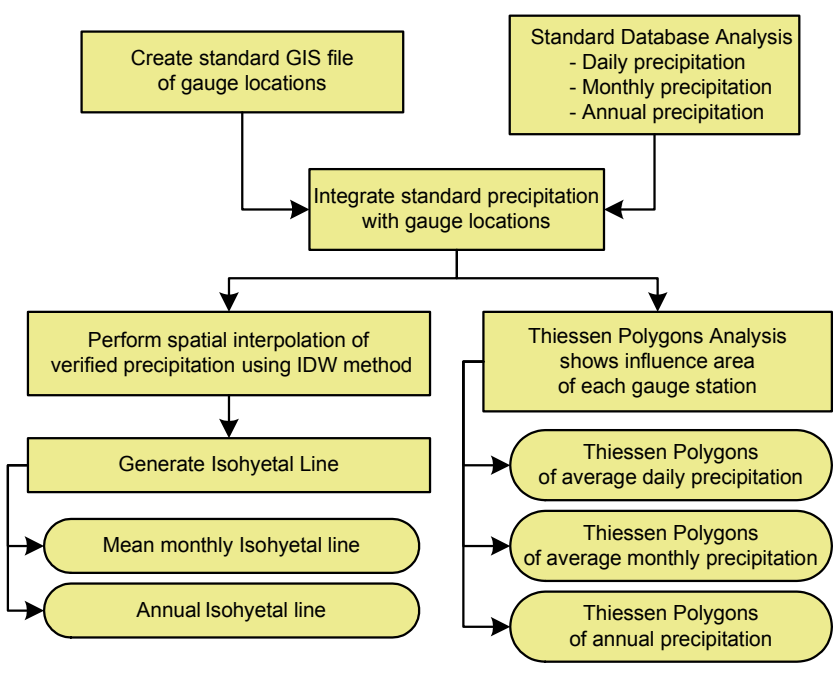

Figure 2

Data process example

precipitation data (140 gauge stations) through spatial distribution (inverse distance-weighted approach) is illustrated in the form of an isohyetal line. Figure 2 illustrates the example process of deriving standard data from original precipitation data.

Interactive or virtual systems for community engagement strategy: While a number of databases are underway in assimilation processes, interactive systems for community engagement are developing, being web-based and GIS through open-source technology. The processes perform under ServerR2 operating system, internet information service IIS6 Web Service, Minnesota MapServer4.8.3, Chameleon2.4, PHP4.4.3, Java Script and HTML GIS. With thin-client approach, the MapServer processes GIS data upon request from each client machine and returns a geo-referenced image. The production can be in GIF, PNG or JPG format through a means of web-map service (WMS). Chameleon2.4, an open-source tool for developing a client-side webmap application, is utilised to customise the GIS web application interface. The system is password protected due to the copyright restrictions of the data. Figure 3 illustrates an overview of the existing Thailand Hydroinformatic System which is distributed through the internet (URL: http://gis.eng.ku.ac.th/ and http:// game t.eng.ku.ac.th/).

As a complement to the 2007 version, additional essential data played a supportive role in layers of administrative boundaries, population, surface water resources, faults, and geology

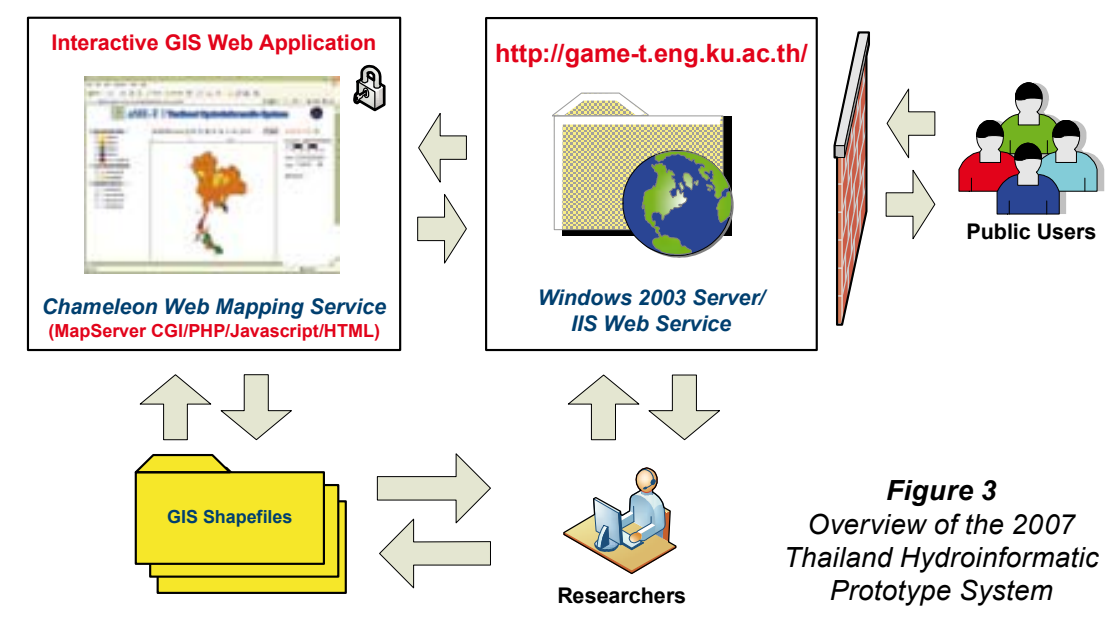




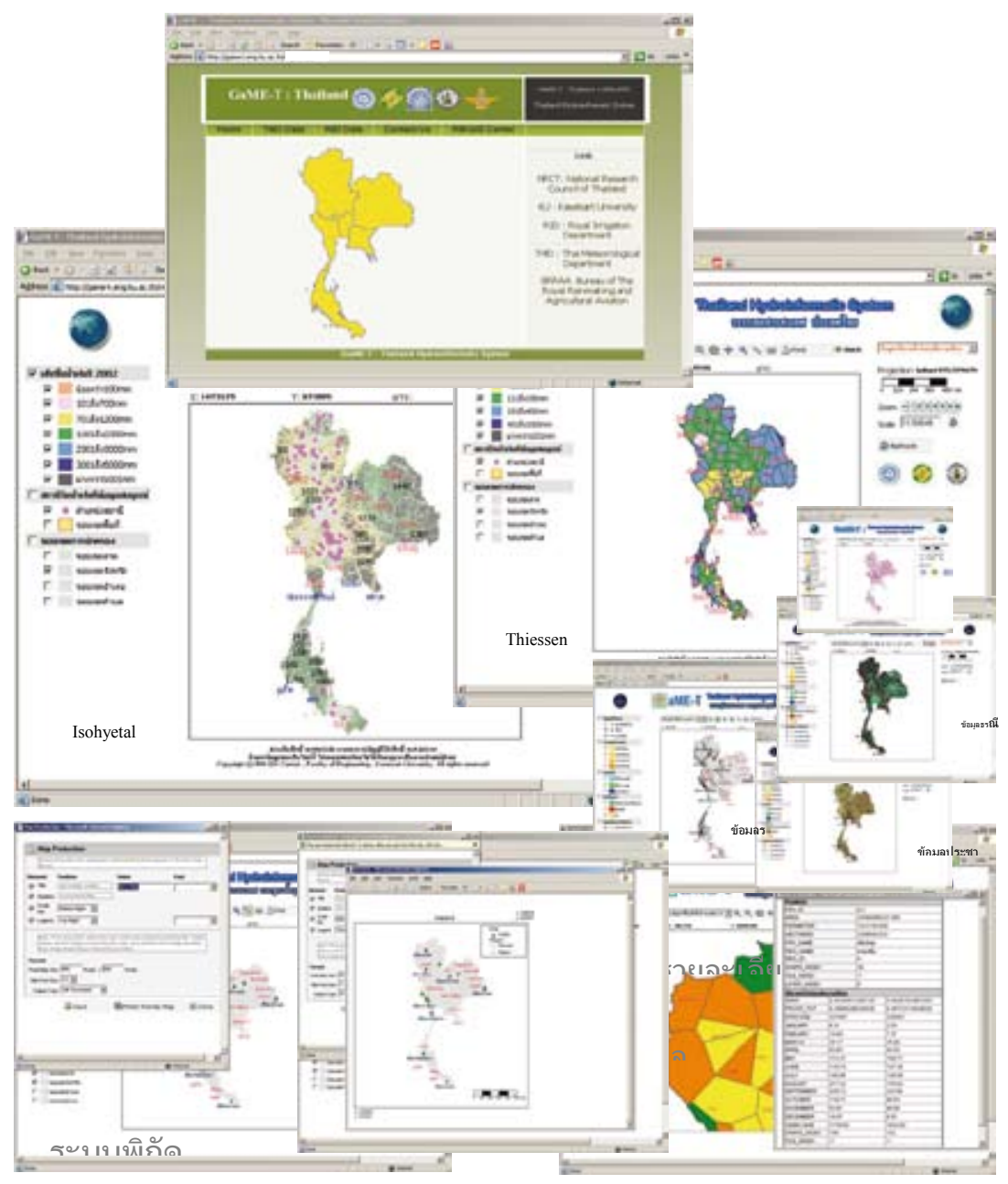

Figure 4

Snapshot of the 2007 Thailand Hydroinformatic Prototype System well as to change spatial referencing systems on-the-fly. Figure 4 presents a snapshot of the 2007 Hydroinformatic System of Thailand.

This interactive system does enlarge potentiality of national communities to realise the potential of their natural water resources and to understand their water environment. Although the 2007 Thailand Hydroinformatic Prototype System is successfully tested and the community is engaged on a national basis, certain limitations of flexibility on data query, analysis and updating still exist. Other system limitations include lack of interoperable data dissemination and slow response time in opening large GIS datasets from remote areas. These limitations have led to the improvement of structural design and methodology development. The new hydroinformatic system aims to overcome exiting limitations in previous versions, adds additional databases and enhances usage through hydrological analysis functions. A more comprehensive improvement of the new system emphasises the national sustainable system to relieve catastrophes, reduce risks and improve water resource management capability. Thus, the new virtual system for 2008 comprises clusters of overlapping networks among tele-metering systems, database management systems, public domain models, user-interface systems and capacity building systems. Figure 5 is a schematic diagram illustrating the 2008 Thailand Hydroinformatic System.

Concurrency and computation can be

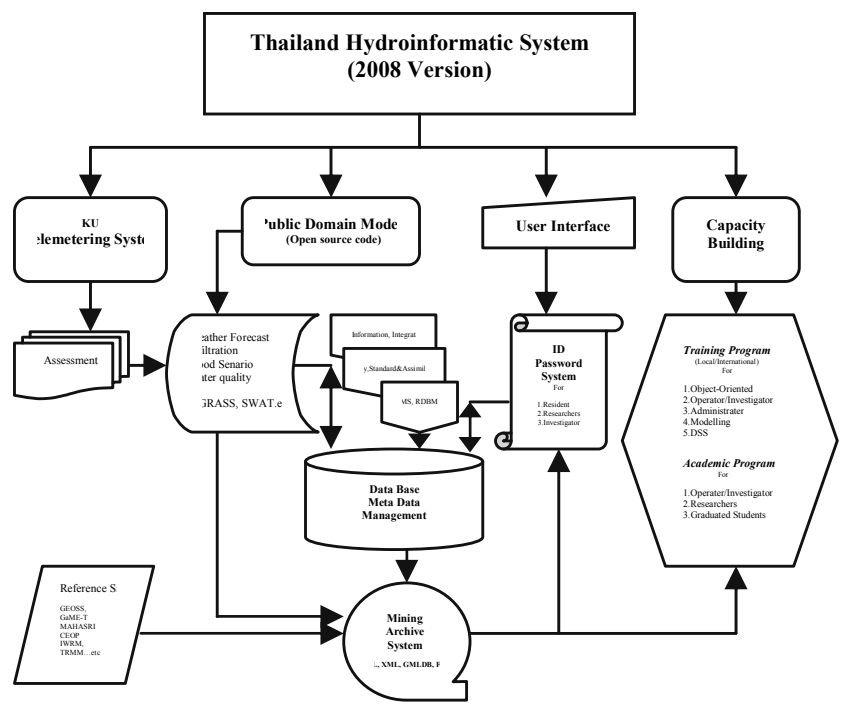

Figure 5

THS 2008-version schematic diagram

data, to increase the potential uses of the system. This system was developed to equip with standard web-based GIS tools including zoom-in, zoom-out, scan, distance measurement, re-centre, and automatic scale bar. It also allows users to select display layers as used in real-time streaming data-grid services and management (Fox et al., 2006) and graphical techniques have their roots in water analysis as applied in continuous processing and mathematical techniques (Gouws et al., 2008). Database improvement of the 2008 version is designed to include the XML-GML generator that offers an interoperable data dissemination. Extensive Markup Language (XML) is the World Wide Web Consortium (W3C) recommendation for data sharing over the internet. It is simple, e easy to read, and effortless to create and process. Geography Markup Language (GML) is an extension of XML to support the modelling of spatial data. GML is developed by Open Geospatial Consortium (OGC) and serves as an open interchange format for disseminating spatial data over the internet (International Standard 19115 Geographic informationMetadata, 2003). To this end, all standard GIS and MIS data will be transferred to store in the central PostgreSQL/PostGIS database. They are being stored in atomic form to allow more flexibility for data query, analysis, and updating. Storing data in the PostgreSQL/PostGIS database also helps to improve data integrity and system security. Database backup and recovery can be accomplished easily through the use of the backup and recovery system provided by PostgreSQL.

In order to achieve on water sectors/stakeholders engagement, Flash is selected to develop lightweight GIS application to offer ease of use for users with minimum GIS background and users in remote areas. Flash was selected because of good 
functionalities to support the development of the user-friendly interface. In contrast to the WMS approach where maps are rendered at server machine and then transferred to client machines in raster format, Flash transfers vector data directly to client machines as maps are drawn on-the-fly from the vector data. This approach helps to reduce workload of the server machine since it no longer needs to perform map rendering. Furthermore, it also helps reducing the size of the file being transferred between client and server machines as well as minimising the reloading process when users zoom in or zoom out.

Server-side/client-side application is rather important to assist the virtual system. GeoServer is selected as a server-side application to publish GIS data through the internet. GeoServer supports both WMS and Web Feature Service (WFS) capabilities, which essentially allow data to transfer in both vector and raster formats. OpenLayers, an open-source Java Script tool for developing client-side web map application, is selected to develop a more sophisticated web-based GIS application for advanced users, complex data analysis and queries. Since both GeoServer and OpenLayer are Java-based, they seamlessly support AJAX technology for better customisation of the user interface.

One of the major objectives of the 2008 system is the ability to predict inundation/drought possibility. Past methodologies suggested coupling geographic information systems with hydrological and hydraulic flood modelling which is essential to water resource management (Correia et al., 1998) and digital elevation model uncertainty could model inundation depths (Yilmaz et al., 2004). The majority of research requests were for five-dimensional flow simulation to solve flood/drought problems which varied from area to area. Further, inundating/drought periods and damage quantities are reticulated to proceed for decision and strategy management. Previous studies suggest that public domain models challenge substantive simulation in flow scenarios (Vathananukij, et al., 2004a; b; c). A representative model with hydraulic gradient and storage deficit below saturation is a rather suitable methodology that could increase simulation accuracy. Specific hydrological concepts for inundation are apparent in the following equations:

$$
S_{i}=\left(\theta_{s}-\theta_{f c}\right)\left(Z_{i}-\psi_{0}\right)=\Delta \theta_{1}\left(Z_{i}-\psi_{0}\right)
$$

where:

$s_{i} \quad=$ local gravity drainage storage deficit

$\theta=$ soil moisture at saturation

$\theta_{f c}^{s}=$ soil moisture at field capacity

$Z_{i}=$ ground water level

$\Delta \theta_{1}=$ effective drained porosity

$\Delta \theta_{2}=$ root zone storage

$\psi_{0}=$ effective depth of capillary fringe

$$
E_{a}=E_{p} \times\left(1-\frac{S_{r z}}{S_{r \max }}\right)
$$

where:

$s_{r z} \quad=$ root zone storage deficit

$s_{r \max }=$ maximum allowable storage deficit

$$
\mathrm{Q}_{b}(t)=T_{0} e^{-\bar{\lambda}} e^{\bar{s}(t) / m}
$$

where:

$$
\begin{aligned}
\mathrm{Q}_{b} & =\text { base discharge } \\
T_{0} & =\text { mean permeability coefficient } \\
\bar{\lambda}^{0} & =1 / \mathrm{A} \int \lambda_{i} \\
\mathrm{~A} & =\text { drainage area }
\end{aligned}
$$

$$
\begin{array}{ll}
\lambda_{i} & =\ln \left(a_{i} / \tan \beta_{i}\right) \\
\bar{s}(t) & =\text { mean storage deficit below saturation } \\
m & =\text { recession curve coefficient }
\end{array}
$$

These specific concepts are presented in the topographic model Grass-KU version (Vathananukij and Nitayawatana, 2008). Therefore, the flow simulation requires integration between open-source Grass GIS, Python Web Processing Service (PyWPS) and Virtual Reality Modeling Language (VRML) technology. Grass GIS serves as the flood analytical component where PyWPS is used to control Grass GIS modules as well as to communicate with the web server. The VRML technology will apply to three-dimensional objects display through standard web browser. Figure 6 illustrates an overview of the effective portion of the 2008 Thailand Hydroinformatic System (THS 2008) which comprises public domain models, database management systems and supporting applications. Figure 7 presents a snapshot of flow simulation module in the 2008 Thailand Hydroinformatic System which is distributed through the internet (URL: http://gis.eng.ku.ac.th/ and http://informatic.eng.ku.ac.th/).

\section{Conclusions}

The knowledge and management of water resources are becoming urgent issues to strengthen and resolve resolve the unpredictable flood/drought nature. The hydroinformatic system is essential to integrate information, transfer knowledge and for strategic planning. Two standard-process versions (under open source licence) have been presented for operations. The hydroinformatic system has proved to be a touchable innovation that could improve the ability of national communities to realise the potential of their natural resources and better understand their water environment. Making its academic debut in June 2007, the KU Awards of Excellence Innovation honoured the Thailand Hydroinformatic System as its best achievement in engineering and architecture improvement with sustainable impact on society. Lessons learnt from 2007 implementation did stimulate the 2008 version to add more dimensions.

Future work will be focused on linking all portions in THS2008. The outcome scenarios are focused on the modern 


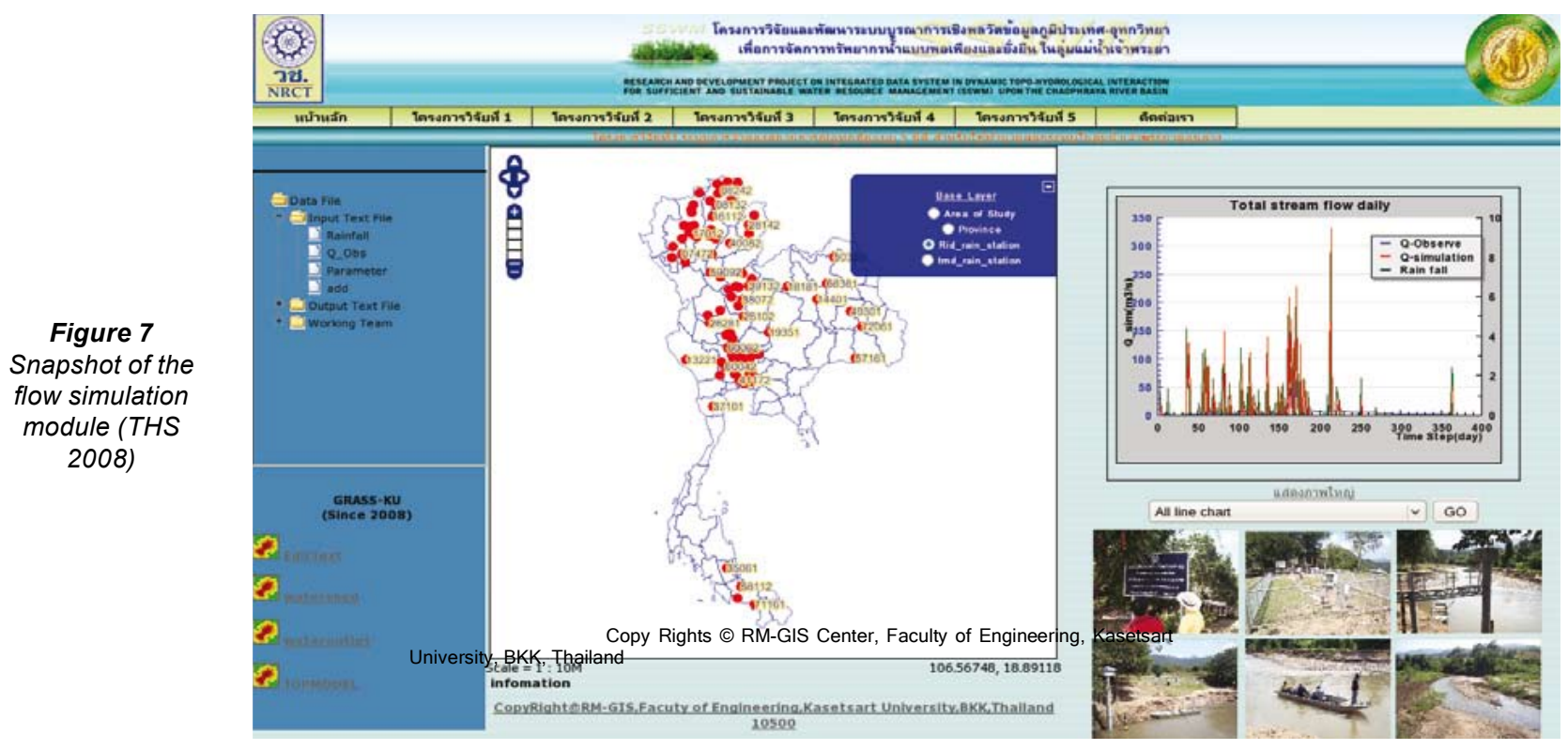

true-scale virtual system which plays an important role as genuine decision supporting system to solve flood/drought problems, prevent catastrophes, reduce risks and improve water resource management capability.

\section{Acknowledgements}

THS researchers gratefully acknowledge the financial support received from the National Research Council of Thailand (NRCT) since 2005. The Thailand Meteorological Department (TMD) and the Royal Irrigation Department (RID) are thanked for data and field experiments; and the Faculty of Engineering - Kasetsart University is gratefully acknowledged for giving advice, opportunity and support.

\section{References}

ADAMS TM, MALAIKRISANACHALEE S, BLAZQUEZ C, LUECK $\mathrm{S}$ and VONDEROHE AP (2002) Enterprise-wide data integration and analysis for OS/OW Permitting. ASCE J. Comput. Civ. Eng. 16 (1) $11-22$.

CORREIA FN, REGO FC, SARAIVA MDG and RAMOS I (1998) Coupling GIS with hydrologic and hydraulic flood modelling. Water Resour. Manage. 12 229-249.

FOX G, AYDIN G, BULUT H, GADGIL H, PALLICKARA S, PIERCE $M$ and WU W (2006) Management of real-time streaming data grid services. Concurrency and Computation: Practice and Experience. Special Issue from Proc. $4^{\text {th }}$ Int. Conf. Grid and Cooperative Computing. 30 November - 3 December 2005, Beijing, China.

GOUWS JF and MAJOZI T (2008) A mathematical technique for the design of near-zero-effluent batch processes. Water $S A 34$ (3) 291368

GYASI-AGYEI Y, WILLGOOSE G and DE TROCH F (1995) Effects of vertical resolution and map scale of digital elevation models on geomorphological parameters used in hydrology. Hydrol. Proc. 9 363-382.

MALAIKRISANACHALEE S and ADAMS TM (2005) Lane-based network for transportation network flow analysis and inventory management. TRR J. Transp. Res. Board 1935 101-110.

MALAIKRISANACHALEE S, VATHANANUKIJ H and THANAPATAY D (2007) Interperable solution for Thailand Hydrological Database. In: Proc. The $120^{\text {th }}$ Anniversary of Japan Thailand Relations/Thailand-Japan Inundatory Mitigation Discourse. 8-10 April 2007, Hilton, Prachuap Khiri Khan, Thailand. Publication No. 6
49-53.

OLIVERA F and MAIDMENT D (1999) System of GIS-based Hydrologic and Hydraulic Application for Highway Engineering, Bureau of Engineering Research, The University of Texas at Austin, Project Summary Report 1738-S.

TSIHRINTZIS VA, HAMID R and FUENTES HR (1996) Use of geographic information system (GIS) in water resources. Water Resour. Manage. 10 251-277.

VATHANANUKIJ H (1998) River Engineering. Physics Center, Bangkok, Thailand. $120 \mathrm{pp}$.

VATHANANUKIJ H (2003) Geoinformatic System / Geographic Information System. Physics Center, Bangkok, Thailand. 151 pp.

VATHANANUKIJ H (2004a) Portentous flood exposition on geoinformatic system. In: Proc. International Symposium on Water Resource and Its Variability in Asia in the 21 $1^{\text {st }}$ Century. 1-2 March 2004, Epochal (International Congress Center), Tsukuba, Ibaraki, Japan. Publication No. 1 25-28.

VATHANANUKIJ H (2004b) Sustention models for water resource management. In: Proc. $2^{\text {nd }}$ APHW Conference jointly with 1st AOGS Annual Meeting. 5-9 July 2004, Suntec International Convention and Exhibition Center, Singapore. Publication AOGS Vol. II 668-676.

VATHANANUKIJ H (2004c) Regulated and unregulated river reach perception through geoinformatic public domain model particularized upon The Chaophraya Tributaries. In: Proc. $6^{\text {th }}$ International Study Conference on GEWEX (The Global Energy and Water Cycle Experiment) in Asia and GAME(GEWEX Asia Monsoon Experiment). 3-5 December 2004, Kyoto International Community House, Kyoto, Japan. Publication No. T7PHV165014 16-23.

VATHANANUKIJ H (2005) Geoinformatics and public domain system model on Thailand mega prototype safety. In: Proc. 4th International Symposium on New Technologies for Urban Safety of Mega Cities in Asia. 18-19 October 2005, Nanyang Technological University, Singapore. Publication No. USMCA2005. 579-584.

VATHANANUKIJ H (2006) EOS imageries and hydrodynamic model for Bangkok flood relief potentially. In: Proc. New Technologies for Urban Safety of Mega Cities in Asia, Phuket, Thailand. Publication No. USMCA2006 1087-1093.

VATHANANUKIJ H (2006) Geoinformatic public domain system model in Thailand. Kasetsart Sci. J. 40 264-272.

VATHANANUKIJ (2007) Hydro-meteorological prediction model. In: Proc. Bali International Meeting 2007.3-9 September 2007, Ramada Bintang, Bali, Indonesia. Publication CEOP/AMY2007 H1-H5.

VATHANANUKIJ H (2008) Water Resource Engineering Innovation (Public Domain System Models SWAT \& GRASS). Aksornsophon, Bangkok, Thailand. $195 \mathrm{pp}$.

VATHANANUKIJ H and NITAYAWATANA P (2008) GRASS in 
Thailand. In: Proc. Asia Oceania Geoscience Society 2008 Conference. 16-20 June 2008, BEXCO, Busan, Korea. Publication AOGSAS16-A010, AS1-10.

VEREGIN H (1997) The effects of vertical error in digital elevation models on the determination of flow-path direction. Cartogr. Geogr.
Inf. Syst. 24 67-79.

YILMAZ MU, USUL N and AKYUREK Z (2004) Modelling the propagation of DEM uncertainty on flood inundation depths. In: Proc. of ESRI International User Conference. August 9-13, 2004. 